\title{
3 Research Soure

\section{The Impact of the Quality of Sexual Education on HIV/AIDS in Zambia: Evidence from a Natural Experiment}

\section{Arlette Simo Fotso}

Centre Population et Developpement https://orcid.org/0000-0002-5006-8105

\section{Sally Findley}

Columbia University

Vesper H. Chisumpa ( $\nabla$ vchisumpa@gmail.com )

https://orcid.org/0000-0003-1234-3644

Karampreet Sachathep

Columbia University

Lloyd B. Mulenga

University of Zambia

Research article

Keywords: HIV/AIDS, quality of sex education, CSE programme, PHIA survey, Zambia

Posted Date: July 21st, 2020

DOI: https://doi.org/10.21203/rs.3.rs-43605/v1

License: (a) (i) This work is licensed under a Creative Commons Attribution 4.0 International License.

Read Full License 
1 The Impact of the Quality of Sexual Education on HIV/AIDS in Zambia: Evidence from a

2 Natural Experiment

3 By

4 Arlette Simo Fosto, Sally Findley ${ }^{\text {II }}$, Vesper H. Chisumpa ${ }^{\text {III }}$, Karampreet Sachathep ${ }^{\text {IV }}$, Lloyd

5 Mulenga $\mathrm{V}$

6 Corresponding author: Arlette Simo Fotso, simofotsoarlette@yahoo.fr, Tel :+33 622449606.

7 CEPED, 45 Rue des Saints-Pères, 75006, Paris, France.

' ICAP at Columbia University, Pretoria, South Africa. Demography and Population Studies, University of the Witwatersrand, Johannesburg, South Africa. Current affiliation: Population and Development Research Centre, French National Research Institute for Sustainable Development, INSERM, Paris, France.

"ICAP at Columbia University, New York, US.

III University of Zambia, Lusaka, Zambia

IV ICAP at Columbia University, New York, US.

${ }^{\vee}$ Ministry of Health Zambia. University of Zambia, Lusaka, Zambia 
Background:

This paper focuses on how sexual education quality is associated with HIV-related knowledge, stigma and risky sexual behaviour among Zambians. The implementation of the Comprehensive Sexuality Education programme since 2014, with sequential in-service teacher training provides a natural experiment for testing the hypothesis that quality of sexual education, not quantity only, is positively associated with HIV knowledge, and negatively associated with risky sexual behaviours and stigma.

Methods:

Data are drawn from the 2016 Zambian Population-Based HIV Impact Assessment survey, which sampled 24,663 individuals aged 15-59 years old nationwide. Province fixed-effects double difference model is used to test our hypothesis.

Results:

We found that sexual education with well-trained teachers reduced the number of HIV-related stigma by 0.13 points, while as expected it was associated with a greater number of correct HIV-related knowledge $(0.29$ points). No significant association was found between quality of sex education and risky sexual behaviours. progression. 
The association between education and HIV prevalence has generally followed the lines of research on the association between education and fertility or child survival. Namely, that education improves how individuals process availability of information about gaining control of their health, whether through improved understanding of promotional materials, changes in their self-efficacy and sense of agency, or through more effective interactions with health care providers. Studies have found that educated individuals tend to adopt more protective behaviours such as condom use, testing for HIV (1-3), and abstaining from sex (4). Using an instrumental variable approach Agüero and Bharadwa (5) found that secondary education reduces the number sexual partners in Zimbabwe and increases comprehensive knowledge about HIV, echoing the results of de Walque in five African countries (1). According to Agüero and Bharadwa (5) this effect could be explained by greater access to media by the more educated, while de Walque (2) points out the greater responsiveness to HIV campaign by educated people. Additional evidence of a negative association between education and HIV incidence is reported by Bärnighausen et al (6), Hargreaves et al. (7) and Jukes et al (8).

However, some studies have found an opposite pattern, namely a positive association between education and HIV prevalence in sub-Saharan Africa (SSA) $(9,10)$. These studies showed that more educated individuals are more likely than the non-educated to adopt risky sexual behaviours such as having more sexual partners $(3,11,12)$, premarital sex (9) or lower abstinence and higher level of infidelity (1).

These differences in the effect of education on the engagement of sexually risky behaviours could reflect differences in the quality of education, namely the quality of content of health educational messages given during the post-primary educational years. This paper examines the effect of the improvement of quality of sexual education on HIV-related knowledge, stigma and risky sexual behaviour, controlling for the number of years of schooling, therefore allowing a separation of the educational effect into quality versus quantity. Zambia is one of the first countries in the SSA region to have initiated a nation-wide scale-up of a Comprehensive Sexuality Education (CSE), which covers relationships, values, attitudes and skills, culture and human rights, human development, sexual behaviours and sexual and reproductive health (13). Since 2014, Zambia has scaled up the implementation of its (CSE) curriculum for grades 5 to 12 (14) with sequential in-service teacher training which has likely created an heterogeneity in the quality of sexual education across the country. Therefore, in this study, 
natural experiment for testing the hypothesis that quality of sex education not quantity of education only is negatively related to risky sexual behaviours and HIV-related stigma and ignorance.

The paper uses data from the Zambia Population-based HIV Impact Assessment (ZAMPHIA) of 2016, which is the first survey to measure the national HIV incidence in Zambia (15). The ZAMPHIA survey enabled estimation of HIV incidence and prevalence for all persons by age and region of residence, including children and adolescents, and also collected detailed information about sexual behaviours, HIV knowledge, stigma, and HIV-prevention behaviours; therefore, it is suitable for assessing differences in risk behaviours, attitudes and knowledge by exposure to the CSE. The date of birth and the region of residence are used to determine whether or not an individual has been exposed to higher quality of sexual education.

\section{Context and CSE program}

Located in southern Africa, Zambia is a land-locked country with a land area of 752,612 square kilometres divided into 10 administrative provinces (16). Its estimated population of 13.1 million in 2010 was very young with more than 50\% under 15 years. Since 2002, primary education is free and compulsory for grades 1 to 7 (17), although the net attendance ratio in primary education remained at $81 \%$ in 2014 . The literacy rate was $83 \%$ among men and 68\% among women aged 15-49 years (16). Zambia, therefore, has made great progress in terms of education since 2007. Since 2002, the government of Zambia has designed several National HIV and AIDS Strategic Frameworks (NASF) to respond to the epidemic. The most recent strategic plan, the Revised National HIV and AIDS Strategic Framework (R-NASF) 2014 - 2016, was designed to provide "adequate space and opportunities for Communities, Civil Society, Private Sector, Development Partners (Bilateral and Multi-lateral Agencies) and Government

92 institutions to actively participate in the implementation of evidence based HIV and AIDS programmes based on 93 their mandates and comparative advantages" (18). These strategies include provision of HIV education through life 94 skills courses, in which CSE features prominently. Since April 2014 a curriculum integrating CSE has been rolled 95 out in all schools across Zambia (14). and relationships by providing scientifically accurate, realistic, non-judgmental information" (19). Even though many countries have implemented such a programme each of them has its own approach (20). In Zambia, the Life- 
Skills Education framework (2011) and Comprehensive Sexuality Education framework (2013) have been merged

100

101

102

103

104

105

106

107

108

109

110

111

112 and included in the school curriculum at national level with the aim to reduce the impact of HIV on young people. The CSE is not a standalone subject, but is integrated into other subjects like social studies, civic education, biology, and home economics. The CSE framework covers several topics, including relationship, values, attitudes and skills, culture and human rights, human development, sexual behaviours and sexual and reproductive health. The targeted population are adolescents from grade 5 to 12 , with the objective to improve their sexual and reproductive health (SRH) (14). By 2015, the CSE programme had reached $100 \%$ of schools, with $77 \%$ of learners from grade 5 to 12 and 38,251 teachers were trained to teach the CSE curriculum (13).

However, in-service teacher training on CSE which prepares teachers to correctly deliver the CSE curriculum was done sequentially in Zambia. It was implemented in the provinces of Lusaka, Eastern and Copperbelt by CSE curriculum specialists in the first year, 2014 (phase 1), and then in 2016 moved to Southern, Western and Central provinces (phase 2) and finally was completed in Luapula, Muchinga, Northern and Northwestern provinces (phase 3) (13). We exploit this sequential implementation of in-service teacher training to capture a variation in quality of sexual education,

\section{Methodology}

\subsection{Data and sample}

The data used for this study are from the Zambian Population-based HIV impact assessment (ZAMPHIA) survey. ZAMPHIA is a nationally representative survey that was conducted between March and August 2016 by the Government of Zambia through the Ministry of Health $(\mathrm{MOH})$, with funding from the U.S. President's Emergency Plan for AIDS Relief (PEPFAR), technical assistance of the U.S. Centers for Disease Control and Prevention (CDC) and implemented by ICAP at Columbia University. The objective of the survey was to provide national and subnational estimates of HIV prevalence and incidence, as well as indicators of HIV risk-behaviours, prevention, and treatment.

ZAMPHIA employed a two-stage stratified cluster sample design, with the selection of enumeration areas (EAs) at the first stage based on information from the 2010 Census of Population and Housing of Zambia, followed by a random selection of households in each enumeration area. In total, 511 EAs and 13,441 households were selected, of which 10,957 households were successfully interviewed. The designated head of household provided consent for the household to participate in the survey, while individuals aged 15-59 years provided consent for the 
individual interview and biomarker component of the survey. ${ }^{\mathrm{VI}}$ The protocol of the survey was reviewed and approved by the Institutional Review Boards/Ethics Committees of the Tropical Diseases Research Centre Zambia, CDC and Columbia University.

Three main questionnaires were used: household, adult individual, and adolescent questionnaires. In this study, only information from the first two questionnaires was used. Overall, 21,280 eligible individuals aged 15-59 years were interviewed, of which 19,115 consented for the biomarker module. Half of the adults were selected for the HIV/AIDS knowledge and attitude module, a total of 10,636 individuals.

\subsection{Identification strategy}

In order to estimate the effect of participation in the CSE curriculum on HIV-related knowledge, discriminatory attitudes and risky behaviours, we used a double difference (DD) approach.

Because only school age children at the time of the introduction of CSE were exposed to the intervention of improved quality of sexual education, the individual's year of birth or age was used to divide the sample into the Pre-CSE and Post-CSE groups, similar to the before/after treatment concept in impact evaluation studies. In Zambia, school (grade 1) starts at the age of 7 , which means that a child reaches grade 5 at age 11 and grade 12 at age 18 (see table 1). In 2014, at the time of the CSE introduction, this age range corresponds to the cohort born between 1996 and 2003. At the time of the survey, in 2016, two additional birth cohorts had been exposed (2004 and 2005). Hence, in 2016, persons aged 11- 20 years, could be considered as part of the Post-CSE cohort. However, in order to ensure comparability between the pre- and post- CSE cohorts, we reduced the age range and the lower bound age for postCSE cohort and limited it to 19. For the same reason, the upper bound age for our comparison cohort was fixed at 22 years. This allows us to create a post-CSE indicator taking the value 1 if the individual is from the cohort 1996-1997 (aged 19-20 in 2016) and 0 if (s)he is from the cohort 1995-1994 (aged 21-22 in 2016).

[table 1 here]

Although the CSE was implemented in the whole country in 2014, the provision of specific support for inservice teacher training was phased. Without adequate training of teachers, the knowledge of the new CSE curriculum is less likely to have been correctly conveyed to students. We therefore have subdivided the provinces into zones, with Zone 1 for individuals living in provinces which received in-service teacher trainings right at the

\footnotetext{
${ }^{\text {VI }}$ Parent's permission and participant's assent were requested for non-emancipated minor aged 15-17.
} 
beginning of the program in 2014, (Lusaka, Eastern and Copperbelt) and Zone 2 for those living in all other provinces, which received the in-service teacher training later on.

The Difference in Difference (DD) model estimated is presented as follows:

$$
Y_{j k}=\beta_{0}+\beta_{1} \text { PostCSE }_{j}+\beta_{2} \text { Zone }_{k}+\beta_{3} \text { PostCSE }_{j} * \text { Zone }_{k}+\beta_{k} X_{j k}+\varepsilon_{j k}(1)
$$

Where $\overline{Y_{j k}}$ are the outcome variables (HIV-related knowledge, discriminatory attitude and risky sexual behaviours) of individual from the cohort $j$, in the zone $k$. (More details about the construction of outcome variables are given in section 3.3.) The interaction between the post-CSE and Zone variables allows identifying the effect of the CSE program on those who were likely to be treated (post-CSE cohort in Zone 1 of in-service teacher training). $X$ is a vector of control variable usually associated with HIV knowledge or risky behaviours. $\overline{\text { PostCSE }}$ is a dummy variable for the post-CSE cohort. It captures aggregate factors that would cause changes in $Y$ of the two cohorts even in the absence of introduction of in-service teacher training for CSE. The dummy variable $\overline{Z o n e}$ captures possible differences between individuals in Zone 1 and those in Zone 2 prior to the introduction of the programme. $\beta_{3}$ is the effect of in-service teacher training for CSE treatment on the treated population.

In addition to a specific control for education level completed, the $\mathrm{X}$ vector includes controls for gender (9), religion, marital status, wealth index, and ethnic background $(2,12,21)$. We also control for HIV status, as it can influence people's HIV-related knowledge, stigma and risky behaviours. Some estimates also control for specific provinces in order to account for regions specificities (more details are given below).

\subsection{Outcome variables}

The first outcome variable used is HIV-related knowledge. The ZAMPHIA survey collected information on five

172 standard HIV-related knowledge questions among adults 15-59 years: whether the risk of HIV transmission can be 173 reduced by having sex with only one uninfected partner who has no other partners; whether a person can reduce the 174 risk of getting HIV by using a condom every time they have sex; whether a healthy-looking person can have HIV; 175 whether a person can get HIV from mosquito bites; and whether a person can get HIV by sharing food with someone who is infected. We constructed an additive index to capture the number of accurate responses, ranging from 0 (for 177 individuals who correctly responded to none of the questions or responded they do not know for all the questions) to 1785 (for individuals who responded correctly to all 5 questions). 
The second outcome variable used in the analysis is HIV related discriminatory attitudes, based on the responses to the following questions: 1) Would you buy fresh vegetables from a shopkeeper or vendor if you knew that this person had HIV? 2) Do you think that children living with HIV should be able to attend school with children who are HIV negative? The index of HIV discriminatory attitude was constructed from the responses to these questions, ranging from 0 if yes to both questions to 2 if no to both questions.

Finally, this study used an index of risky sexual behaviour in the past 12 months as an outcome variable. Five sexual behaviours were included in this additive index of number of risky sexual behaviours: 1) not all sexual partners in the last 12 months were spouse or living-in partners; 2) condom not used during sexual intercourse with non-marital sexual partner; 3) individual engaged in paid sexual intercourse (sold or bought) the last 12 months; 4) individual did not use condom during paid sexual intercourse; and 5) person had more than two sexual partners in the last 12 months. The index of sexual risky behaviour ranges from 0 , for those who did not have any of these behaviours, to 5 , for individuals who cumulated all these risky sexual behaviours. Because abstinence can also be a strategy adopted by an individual to avoid HIV and STIs, those who did not have sex during the last 12 months are also considered as having 0 sexual risky behaviours.

\subsection{Robustness check}

Our identification strategy can raise a number of biases. First, different regions can have different infection patterns, because of the prevalence of HIV in the locality. These differences in prevalence could lead to provincewide differences in HIV-related knowledge, stigma and risky behaviours. Failing to account for these regional differences could imply that the changes are due to the effect of in-school teacher training for CSE when actually they are attributable to the provincial HIV context. To address this issue, we included province residence dummies for region fixed-effects estimations. This also controls for the heterogeneity in the timing of in-service teacher training in Zone 2. When we include region dummies, we use a fixed effects Difference in Difference model presented in equation 2 .

$$
Y_{j k}=\delta_{k}+\beta_{1} \text { PostCSE }_{j}+\beta_{4} \text { PostCSE }_{j} * \text { Zone }_{k}+\beta_{k} X_{j k}+\varepsilon_{j k}(2)
$$

Where $\sqrt{\delta_{\mathrm{k}}}$ is the province fixed-effect. It is important to note that because the zone variables are collinear with the province dummies, the estimation controlling for province fixed-effects do not include this variable.

Second, all our dependent variables are normally distributed continuous variables. A number of statistical tests, presented in annex $2 \mathrm{a}, 2 \mathrm{~b}$ and $2 \mathrm{c}$ in Additional file 1 were performed in order to determine the type of count 
model to be used (22). Poisson regression was used for the HIV-related knowledge index. The test performed in annex $2 \mathrm{~b}$ showed that the most appropriate count model for the stigma variable is a Negative Binomial model (NB). In the NB model, the conditional mean of the outcome given the value of predictors is the same as the one for the standard Poisson, but the variance is different. In NB, variance account for the over-dispersion coefficient. If overdispersion coefficient equal zero, the NB is identical to the Poisson model. (See the third column of table 4 for the

212 NB robustness check).

213 Finally, as pointed out by $\mathrm{Hu}$ et al. (23), if the zero observed can have two origins, as it does for sexual risky behaviour (those who will never engage in risky sexual intercourse and those who might have risky sexual intercourse) and because of the statistical test ( see annex 2c ), sexual risky behaviour was fitted using a Zeroinflated Poisson regression (ZIP). The first step of the ZIP uses a logistic regression to estimate the probability that each individual with a zero value is in each of two latent groups. Then, the Poisson regression is used for the part of the data that does not contain those who will never have risky sexual behaviours. See columns three and four of table 4 for the ZIP model results).

Third, in order to further test the identification strategy, we constructed a 'placebo' treated group. The placebo treated group (aged 21-22 in 2016) is compared to another control group (aged 23-24 in 2016). In principle, both have not been exposed to the programme, hence we should not observe any significant effect of the treatment on outcomes. The non-significance of our variables of interest in placebo estimations would provide suggestive evidence that our DDs, although imprecisely estimated, are not driven by inappropriate identification assumptions (24). stratification to control for non-response; variance estimates are calculated using the Jack-knife replicate weights.

\section{Results}

\subsection{Descriptive statistics}

Table A1 in Additional file 1 presents a general description of the study population. Overall, 3,175 individuals aged 19-21 were selected and responded to the individual interview, of which almost half responded to the HIV/AIDS knowledge and attitude module during the survey (1,603 individuals). The Pre-CSE and post-CSE cohorts had in general a similar number of correct HIV-related knowledge, discriminatory attitude and risky sexual behaviour as shown in Table A1. 

teachers were trained in 2014 to deliver quality sexual education, the post-CSE cohorts have 0.08 higher HIV-related

237 knowledge than their pre-CSE peers of the same zone. Opposite changes were observed where there were delays in

238 implementing in-service teacher training for quality CSE: the number of HIV-related correct knowledge is slightly lower in post-CSE cohorts compared to pre-CSE cohorts (-0.15). The range of contrast in HIV knowledge scores was 0.23 points between the two implementation zones, a statistically significant difference from pre to post-CSEin the two zones.

[table 2 here]

Concerning the HIV-related stigma, the difference of differences shows that individuals from post-CSE cohorts in the zone of early in-service teacher training for CSE implementation have 0.09 fewer discriminatory attitudes. As with the HIV-knowledge scores, in the zone of late in-service teacher training for CSE implementation the pre-CSE cohorts have fewer discriminatory attitudes than the post-CSE ones, with a difference of 0.04 . HIV-related risky sexual behaviours in the previous 12 months.

\subsection{Effect of quality of sexual education on HIV-related knowledge, discriminatory attitudes and risky} sexual behaviours

Table 3 presents the DD regression of the HIV-related knowledge regression. Model 1 presents the estimates of DD as expressed in equation 1. Everything being equal, the number of correct HIV-related knowledge is 0.20 points lower for individuals from the post-CSE cohort compared to the those from the pre-CSE in the zone of late inservice teacher training CSE implementation. The number of correct HIV-related knowledge of an individual in the zone of early in-service teacher training CSE implementation is 0.29 points lower, compared to those in the zone of late in-service teacher training CSE implementation. However, the zone-cohort interaction term shows that for the 257 post-CSE cohort, living in the zone of early in-service teacher training CSE implementation increases significantly 258 the number of correct HIV-related knowledge reported by 0.29 points. Greater wealth and higher education levels also increase HIV-knowledge, with the secondary or higher education having the greatest effect on knowledge. 
Model 2 shows the results of the DD with province fixed effects as modelled in equation 2 to account for the region-specific effects. Very similar results are obtained: the effect of exposure to the CSE curriculum for post-CSE cohort living in the in-service teacher training early implementation zone is an increase of 0.29 points. As shown in

264 Model 1, both wealth and secondary or more education are associated with greater HIV knowledge. The robustness check with a non-linear model (Model 3) yields similar results as Models 1 and 2.

Turning now to the models estimating the effects of the quality sexual education on HIV-related discriminatory attitudes (Table 4), controlling for all socio-demographic characteristics, model 1 also shows the importance of the interaction between being in the early in-service teacher training implementation zone and post-

269 CSE cohort, where the combined effect was 0.12 points fewer HIV-related discriminatory attitudes. When using

270 region fixed effects in Model 2, the number of discriminatory attitudes of 0.13 points is significantly lower among 271 post-CSE cohorts of the early in-service teacher training implementation zone 1. As in the HIV-knowledge models, 272 after controlling for zone and cohort, there are additional education "quantity" effects on reducing the number 273 discriminatory attitudes. Greater wealth is also associated with reductions in discriminatory attitudes. 274 Discriminatory attitudes are also lower among couples and HIV positive individuals. Model 3 shows that robustness check with the NB regression further highlights the significance of these factors.

Table 5 presents the results of the DD regression for risky sexual behaviours. There is no significant 278 difference in the number of risky sexual behaviours between the two zones of in-service teacher training for CSE 279 implementation for pre-CSE cohorts. However, there is a significant reduction in risky behaviours in the post-CSE cohort, as compared to the pre-CSE cohort in zone of late of in-service teacher training for CSE implementation (0.19 points). The same conclusion is obtained with the model with province fixed effects (model 2) and the nonlinear ZIP regression (model 3). For this latter model, there is a significant increase in the probability of never have had sex and a reduction of the number of risky sexual behaviours for post-CSE cohort in zone 2. After controlling

284 for all other variables, the number of risky sexual behaviours is significantly higher among males, 285 divorced/separated/widowed and HIV positive individuals and lower among the wealthier and those in unions. 

no significance of the interaction term coefficients for all the outcomes. This provides confidence that the results obtained are not just driven by the difference that can be found between younger and older cohorts.

\section{Discussion}

The differential timing of implementing a high-quality sexual education in Zambia provided a natural experiment for disentangling the effect of the quality of health-related education from simple years of educational attainment. For measures of HIV knowledge, discriminatory attitudes, our study shows that children who received the quality CSE through early implementation of in-service teacher training had more favourable knowledge and attitudinal outcomes.

When we control for grade, province-specific characteristics, the effects of exposure to the quality CSE remain strong. Our statistical analyses reflect the same findings on the importance of the new CSE programme on HIV knowledge noted in the focus group conducted for the Monitoring and Evaluation of the CSE programme (13).

Contrary to previous research (25), after controlling for exposure to the quality sexual education program of the CSE, we found that the more educated reported less discriminatory attitudes compared to the less educated. This finding suggests that the exposure to the CSE may have increased the ability of those who had attended the CSE program to use their additional schooling to better understand the real nature of HIV, reducing the stigma component related to poor understanding of the epidemic.

The findings for the effect of quality sexual education on risky sexual behaviours differed from those for knowledge and attitudes in their absence of an effect of the timing of in-service teacher training for the CSE implementation. The lack of a quality sexual education effect on subsequent sexual behaviour changes may reflect the need for a longer time frame. Behavioural change is a process more than an event and can take many stages $(26,27)$. There were also, in general no effects of level education on risky sexual behaviours.

Once again, the results using and an older cohort as placebo for treated group showed non-significant results, providing more confidence to our identification strategy.

After controlling for exposure to a quality sexual education program, our study also documents the independent and additional effect of secondary or higher education on HIV-knowledge and reduction of 

individuals to read and process health related information, as well as the content or quality of the health-related materials to which they are exposed in school. These effects are strong for the knowledge and attitudinal domains, and do not carry over into behaviour. As meta-analytic review by Smoak et al. (28), which concluded that HIV-risk interventions neither increased nor decreased sexual occasions and number of sexual partners, our study showed no significant independent effect of additional years of education on risky sexual behaviours.

The aim of this study was to assess the effect of the quality of sexual education on HIV-related knowledge, discriminatory attitudes and risky sexual behaviours in Zambia. We used the data of the ZAMPHIA survey conducted in 2016. The introduction of quality sexual education in 2014 through the CSE programme implementation with sequential in-service teacher training across the provinces of the country provides us with a natural experiment to assess the effect of a quality sexual education. We used fixed-effects double difference approaches and found a number of significant results.

First, we found that the improvement of the quality of sexual education offered by teachers well-trained to deliver the CSE programme increased the number of correct HIV-related knowledge by 0.29 points. Second, the implementation of quality sexual education reduced the number of HIV-related discriminatory attitudes by 0.13 points for the exposed group in zones which first received in-service teacher training, compared to the unexposed cohort. Third, no significant effect was found for the number of risky sexual behaviours.

There are several limitations to our study. First, because we are not using an experimental design, the identification strategy could be imperfect, notably in terms of the comparability of our exposed and unexposed groups. However, we reduced significantly this potential problem by controlling for observables and nonobservables specific to each province through province fixed-effect analyses and by reducing the age range of our sample. Second, it would have been interesting to assess the change in HIV incidence since the introduction of CSE. Although, the ZAMPHIA survey allows identifying HIV infections that occurred 130 days before the survey, we could not conduct analyses of incidence because of the limited numbers of new HIV infections in our age group (only 8 cases). Having new infections for the whole period covered by CSE would allow better estimates of the effect of the CSE program on the HIV pandemic progression. 
Nevertheless, this study contributes to the literature in many ways. By taking advantage of the introduction of a better-quality sexual education with sequential in-service teacher training in 2014 for a natural experiment, we were able to split the effect of education into quality versus quantity of education. Our study shows the importance of considering the quality of sexual education when assessing the relation between education and HIV-related knowledge and behaviours. Second, the study analyses the effect of quality sex education on both HIV-related knowledge, discriminatory attitudes and risky sexual behaviours using additive indexes for each HIV-related variable.

With this specificity, the study provides actionable results to those seeking to further reduce HIV incidence and HIV-related stigma, namely the importance of well-trained teachers who can capably deliver a quality comprehensive sexual education program across multiple grades. The investment in scaled-up quality of sexual education could be an efficient way to reduce the progression of HIV/AIDS and other sexually transmitted infections. Zambia is one of the first countries to implement such a nation-wide programme to improve the quality of sexual education in a school setting (13). This programme should be replicated in other countries in the SSA region.

\begin{tabular}{|c|c|c|c|c|c|c|c|c|c|c|c|c|c|c|}
\hline \multirow{3}{*}{$\begin{array}{l}\text { level } \\
\text { Grade }\end{array}$} & \multicolumn{7}{|c|}{ Primary (compulsory) } & \multicolumn{2}{|c|}{ Lower secondary } & \multicolumn{3}{|c|}{ Upper Secondary } & & \\
\hline & \multirow[b]{2}{*}{1} & \multirow[b]{2}{*}{2} & \multirow[b]{2}{*}{3} & \multirow[b]{2}{*}{4} & \multicolumn{8}{|c|}{ Grades with CSE in 2014} & & \\
\hline & & & & & 5 & 6 & 7 & 8 & 9 & 10 & 11 & 12 & & \\
\hline & & & & & \multicolumn{8}{|c|}{ Age groups corresponding to CSE in 2014} & & \\
\hline \multirow[t]{2}{*}{ Age } & 7 & 8 & 9 & 10 & 11 & 12 & 13 & 14 & 15 & 16 & 17 & 18 & 19 & 20 \\
\hline & & & & & \multicolumn{10}{|c|}{ Age groups exposed to CSE in 2016} \\
\hline Age & 7 & 8 & 9 & 10 & 11 & 12 & 13 & 14 & 15 & 16 & 17 & 18 & 19 & 20 \\
\hline
\end{tabular}

Source: By the authors, based on data reported in UNESCO 2016.

Table 2: Outcome variables by grade completion cohort and CSE implementation zone 
differences

\begin{tabular}{|c|c|c|c|c|c|}
\hline & Mean & SE & Mean & $\mathbf{S E}$ & \\
\hline \multicolumn{6}{|c|}{ HIV-related knowledge } \\
\hline Pre-CSE cohort & 4,02 & 0,05 & 4,10 & 0,06 & \\
\hline Post-CSE cohort & 4,10 & 0,05 & 3,96 & 0,08 & \\
\hline Pre-Post Difference & 0,08 & & $-0,15$ & & $0,23 * *$ \\
\hline \multicolumn{6}{|l|}{ HIV -related } \\
\hline \multicolumn{6}{|c|}{ discriminatory attitude } \\
\hline Pre-CSE cohort & 0,34 & 0,03 & 0,39 & 0,05 & \\
\hline Post-CSE cohort & 0,29 & 0,03 & 0,43 & 0,05 & \\
\hline Pre-Post Difference & $-0,05$ & & 0,04 & & $-0,09$ \\
\hline \multicolumn{6}{|c|}{ HIV-related risky sexual } \\
\hline \multicolumn{6}{|l|}{ behaviour } \\
\hline Pre-CSE cohort & 0,72 & 0,04 & 0,76 & 0,06 & \\
\hline Post-CSE cohort & 0,66 & 0,04 & 0,67 & 0,05 & \\
\hline Pre-Post Difference & $-0,06$ & & $-0,09$ & & 0,03 \\
\hline Observations & 2192 & & 983 & & \\
\hline
\end{tabular}

Note: All the figures are weighted using PHIA appropriate weights. P-value are P values from the t-test of means

363 difference. The observations for HIV-related knowledge and attitudes are 1097 and 506 for zone 1 and zone 2

364 respectively.

Table 3: Difference in Differences regression of HIV-related knowledge in Zambia. 


\begin{tabular}{|c|c|c|c|}
\hline & Model 1 & Model 2 & Model 3 \\
\hline & Coef/(SE) & Coef/(SE) & Coef/(SE) \\
\hline \multirow[t]{2}{*}{ Post-CSE } & $-0.20 * *$ & $-0.20 * *$ & $-0.05 * *$ \\
\hline & $(0.09)$ & $(0.09)$ & $(0.02)$ \\
\hline \multirow[t]{2}{*}{ Early implementation zone 1} & $-0.29 * * *$ & & \\
\hline & $(0.08)$ & & \\
\hline \multirow[t]{2}{*}{ Post-CSE *Zone 1} & $0.29 * *$ & $0.29 * *$ & $0.07 * *$ \\
\hline & $(0.11)$ & $(0.11)$ & $(0.03)$ \\
\hline \multirow[t]{2}{*}{ Male } & $0.10^{*}$ & $0.10^{*}$ & $0.02 *$ \\
\hline & $(0.06)$ & $(0.06)$ & $(0.01)$ \\
\hline \multirow[t]{2}{*}{ Wealth index } & $0.10^{* * *}$ & $0.12 * * *$ & $0.03 * * *$ \\
\hline & $(0.03)$ & $(0.03)$ & $(0.01)$ \\
\hline \multicolumn{4}{|l|}{ Education } \\
\hline \multirow[t]{2}{*}{ Primary } & 0.11 & 0.12 & 0.03 \\
\hline & $(0.22)$ & $(0.22)$ & $(0.06)$ \\
\hline \multirow[t]{2}{*}{ Secondary } & $0.52 * *$ & $0.53 * *$ & $0.14 * *$ \\
\hline & $(0.22)$ & $(0.22)$ & $(0.06)$ \\
\hline \multirow[t]{2}{*}{ More than secondary } & $0.95 * * *$ & $0.96^{* * *}$ & $0.23 * * *$ \\
\hline & $(0.23)$ & $(0.23)$ & $(0.06)$ \\
\hline \multicolumn{4}{|l|}{ Marital status } \\
\hline Married or living together & -0.00 & -0.00 & -0.00 \\
\hline
\end{tabular}


$(0.08)$

(0.08)

(0.14)
0.22

(0.14)

0.13

(0.09)

HIV positive

Divorced/Sep./Widowed

Region fixed-effects

1428

Observations
(0.09)

No

1428

1428

(0.09)

(0.02)

Yes

No

1428

(0.02)

$0.22 \quad 0.06$

(0.03)

$\begin{array}{ll}0.14 & 0.03\end{array}$

Note: Significance levels: $* \mathrm{p}<0.1,{ }^{* *} \mathrm{p}<0.05, * * * \mathrm{p}<0.01$. Coef: coefficient, SE: Standard error. All the estimations are weighted using PHIA knowledge weights. Additional control variables are ethnic group and religion.

369 The knowledge and attitude estimations are based on a subsample randomly selected from individuals eligible for 370 the individual survey.

371

372 Table 4: Difference in Differences regression of HIV-related discriminatory attitudes in Zambia.

\begin{tabular}{lccc}
\hline & Model 1 & Model 2 & Model 3 \\
\hline & Coef/(SE) & Coef/(SE) & 0.10 \\
\hline Post-CSE & 0.04 & 0.05 & $(0.18)$ \\
& $(0.07)$ & $(0.07)$ & \\
Early implementation zone 1 & -0.01 & & \\
& $(0.07)$ & & $-0.39 *$ \\
Post-CSE *Zone 1 & -0.12 & $-0.13 *$ & $(0.20)$ \\
& $(0.08)$ & $(0.08)$ & 0.08
\end{tabular}


Wealth index

Education

Primary

Marital status

Married or living together

Divorced/Sep/Widowed

HIV positive
$-0.10 * *$

0.05

$-0.21 * * *$

(0.05)
$-0.09 *$

0.06

0.14

(0.09)

$-0.21 * * *$

$-0.93 * * *$

(0.06)

\begin{tabular}{llll}
\hline Region fixed-effects & No & Yes & No \\
& & & \\
\hline Observations & 1420 & 1420 & 1420
\end{tabular}

Table 5: Difference in differences regression of HIV-related risky sexual behaviours in Zambia. 


\begin{tabular}{|c|c|c|c|c|}
\hline & \multirow[t]{2}{*}{ Model 1} & \multirow[t]{2}{*}{ Model 2} & \multicolumn{2}{|c|}{ Model 3} \\
\hline & & & Inflated & Count \\
\hline & Coef/(SE) & Coef/(SE) & Coef/(SE) & Coef/(SE) \\
\hline \multirow[t]{2}{*}{ Post-CSE } & $-0.19 * *$ & $-0.19 * *$ & $0.46^{*}$ & -0.11 \\
\hline & $(0.07)$ & $(0.07)$ & $(0.27)$ & $(0.09)$ \\
\hline \multirow[t]{2}{*}{ Early implementation zone 1} & -0.08 & & & \\
\hline & $(0.07)$ & & & \\
\hline \multirow[t]{2}{*}{ Post-CSE *Zone 1} & 0.05 & 0.04 & -0.10 & 0.03 \\
\hline & $(0.09)$ & $(0.09)$ & $(0.39)$ & $(0.13)$ \\
\hline \multirow[t]{2}{*}{ Male } & $0.28 * * *$ & $0.29 * * *$ & $-0.49 * *$ & $0.18 * *$ \\
\hline & $(0.05)$ & $(0.05)$ & $(0.20)$ & $(0.07)$ \\
\hline \multirow[t]{2}{*}{ Wealth index } & $-0.14 * * *$ & $-0.12 * * *$ & 0.16 & $-0.10 * *$ \\
\hline & $(0.02)$ & $(0.03)$ & $(0.13)$ & $(0.04)$ \\
\hline \multicolumn{5}{|l|}{ Education } \\
\hline \multirow[t]{2}{*}{ Primary } & 0.10 & 0.11 & -0.39 & 0.02 \\
\hline & $(0.14)$ & $(0.14)$ & $(0.72)$ & $(0.23)$ \\
\hline \multirow[t]{2}{*}{ Secondary } & 0.07 & 0.07 & -0.73 & -0.17 \\
\hline & $(0.14)$ & $(0.14)$ & $(0.68)$ & $(0.23)$ \\
\hline \multirow[t]{2}{*}{ More than secondary } & -0.02 & -0.03 & -1.64 & $-0.56^{*}$ \\
\hline & $(0.16)$ & $(0.16)$ & (1.02) & $(0.30)$ \\
\hline
\end{tabular}

Marital status 
Married or living together

Divorced/Sep./Widowed

$0.18 *$
$-0.74 * * *$

(0.06)

$0.30 * * *$

(0.11)

(0.10)
$3.35 * * *$

$0.47 * * *$

HIV positive

No

Yes

Yes

Yes

2758

2758

Note: Significance levels: ${ }^{*} \mathrm{p}<0.1, * * \mathrm{p}<0.05, * * * \mathrm{p}<0.01$. Coef: coefficient, SE: Standard error. All the estimations are weighted using PHIA individual weights. Additional control variables are ethnic group and religion.

The risky behaviour estimations are based on respondents who ever had sexual intercourse.

Declarations

Funding: PHIA project is supported by the U.S. President's Emergency Plan for AIDS Relief (PEPFAR) through CDC under the terms of the cooperative agreement U2GGH001226. The contents of this document do not necessarily reflect the views of the United States Government.

Competing Interests: The authors declare that they have no conflict of interest.

Authors' contributions: All authors contributed to the study conception and design. ASF developed the concept note and analysed data for this study. Data were collected by KS and LM. The first draft of the manuscript was written by ASF, and SF and VC commented on and discussed previous versions of the manuscript. All authors read and approved the final manuscript.

Ethics approval and consent to participate: The procedures used in this study adhere to the tenets of the Declaration of Helsinki. Ethical approval for the ZAMPHIA survey was granted by the Zambia National Health Research Ethics Board (Ref: MH/101/23/10-1), the Tropical Diseases Research Centres Ethics Review Committee (Ref: STC/2015/9), and the Institutional Review Boards at the Centres for Disease Control and Prevention (CDC; Atlanta, Georgia, USA) (Ref: \#6760). 
Acknowledgements: Not applicable

400

List of abbreviations

401 CDC: U.S. Centers for Disease Control and Prevention

402 CSE: Comprehensive Sexuality Education

403 DD: double difference

404 EA: enumeration areas

405 MOH: Ministry of Health

406 NASF: National HIV and AIDS Strategic Frameworks

407 NB: Negative Binomial model

408 PEPFAR: U.S. President's Emergency Plan for AIDS Relief

409 R-NASF: Revised National HIV and AIDS Strategic Framework

410 SRH: sexual and reproductive health

411 SSA: sub-Saharan Africa

412 ZAMPHIA: Zambian Population-Based HIV Impact Assessment survey

413 ZIP: Zero-inflated Poisson regression

$414 \quad$ Additional file

$415 \quad$ File name: Additional file 1

$416 \quad$ File format: pdf

417 Title of data: Annex 


\section{References}

1. de Walque D. Does Education Affect HIV Status? Evidence from five African Countries. World Bank Econ Rev. 2009 Jun 1;23(2):209-33.

2. de Walque D. How does the impact of an HIV/AIDS information campaign vary with educational attainment? Evidence from rural Uganda. J Dev Econ. 2007 Nov 1;84(2):686-714.

3. Gummerson E. Have the educated changed HIV risk behaviours more in Africa? Afr J AIDS Res. 2013 Sep 1;12(3):161-72.

4. Alsan MM, Cutler DM. Girls' education and HIV risk: Evidence from Uganda. J Health Econ. 2013 Sep 1;32(5):863-72.

5. Agüero JM, Bharadwaj P. Do the More Educated Know More about Health? Evidence from Schooling and HIV Knowledge in Zimbabwe. Econ Dev Cult Change. 2014 Apr 1;62(3):489-517.

6. Bärnighausen T, Hosegood V, Timaeus IM, Newell M-L. The socioeconomic determinants of HIV incidence: evidence from a longitudinal, population-based study in rural South Africa. AIDS Lond Engl. 2007 Nov;21 Suppl 7:S29-38.

7. Hargreaves JR, Bonell CP, Boler T, Boccia D, Birdthistle I, Fletcher A, et al. Systematic review exploring time trends in the association between educational attainment and risk of HIV infection in sub-Saharan Africa. AIDS Lond Engl. 2008 Jan 30;22(3):403-14.

8. Jukes M, Simmons S, Bundy D. Education and vulnerability: the role of schools in protecting young women and girls from HIV in southern Africa. AIDS Lond Engl. 2008 Dec;22 Suppl 4:S41-56.

9. Fortson JG. The Gradient in Sub-Saharan Africa: Socioeconomic Status and HIV/AIDS. Demography. 2008 May;45(2):303-22.

10. UNAIDS. Report on the global AIDS epidemic [Internet]. Geneva: UNAIDS, World Health Organization; 1998 [cited 2018 Oct 15] p. 72. Available from: http://data.unaids.org/pub/report/1998/19981125_global_epidemic_report_en.pdf

11. Glick PJ, Sahn DE. Are Africans Practicing Safer Sex? Evidence from Demographic and Health Surveys for Eight Countries. Econ Dev Cult Change. 2008 Jan 1;56(2):397-439.

12. Lucas AM, Wilson NL. Schooling, Wealth, Risky Sexual Behaviour, and HIV/AIDS in Sub-Saharan Africa. J Dev Stud. 2018 Jul 16;0(0):1-16.

13. UNESCO. Strengthening comprehensive sexuality education for young people in school settings in Zambia: a review and documentation of the scale-up process [Internet]. France: UNESCO; 2016 [cited 2018 Aug 22] p. 96. Available from: https://hivhealthclearinghouse.unesco.org/library/documents/strengtheningcomprehensive-sexuality-education-young-people-school-settings

14. UNFPA. Emerging Evidence, Lessons and Practice in Comprehensive Sexuality Education, a global review UNFPA - United Nations Population Fund [Internet]. UNESCO; 2015 [cited 2017 Sep 23] p. 47. Available from: http://www.unfpa.org/publications/emerging-evidence-lessons-and-practice-comprehensive-sexualityeducation-global-review

15. Ministry of Health, Zambia. Zambia Population-based HIV Impact Assessment (ZAMPHIA) 2016: First Report. [Internet]. Zambia: Ministry of Health; 2017 Dec [cited 2018 Oct 16] p. 79. Available from: 

Report_11.30.17_CK.pdf

16. Central Statistical Office/Zambia, Ministry of Health/Zambia, I. C. F. International. Zambia Demographic and Health Survey 2013-14 [Internet]. 2015 [cited 2017 Sep 23]. Report No.: FR304. Available from: http://dhsprogram.com/publications/publication-fr304-dhs-final-reports.cfm

17. MESVTEE. Zambia : Education for All 2015 national review [Internet]. Ministry of Education, Science, Vocational Training and Early Education; 2015 p. 45. Available from: http://unesdoc.unesco.org/images/0023/002315/231573e.pdf

18. Republic of Zambia. National HIV/AIDS Strategic Framework 2014-2016. Zambia: NAC; 2014 p. 96.

19. UNESCO. International Technical Guidance on Sexuality Education: An Evidence-informed approach for schools, teachers and health educators [Internet]. UNESCO; 2009 [cited 2017 Sep 23] p. 123. Available from: http://www.siecus.org/index.cfm?fuseaction=Feature.showFeature\&FeatureID=1851

20. Fonner VA, Armstrong KS, Kennedy CE, O’Reilly KR, Sweat MD. School Based Sex Education and HIV Prevention in Low- and Middle-Income Countries: A Systematic Review and Meta-Analysis. PLOS ONE. 2014 Mar 4;9(3):e89692.

21. de Walque D. Who Gets AIDS And How? The Determinants Of HIV Infection And Sexual Behaviors In Burkina Faso, Cameroon, Ghana, Kenya, And Tanzania [Internet]. The World Bank; 2006 Feb [cited 2017 Sep 21]. Available from: https://elibrary.worldbank.org/doi/abs/10.1596/1813-9450-3844

22. Winkelmann R. Econometric Analysis of Count Data [Internet]. 5th ed. Berlin Heidelberg: Springer-Verlag; 2008 [cited 2018 Oct 5]. Available from: //www.springer.com/gp/book/9783540776482

23. Hu M-C, Pavlicova M, Nunes EV. Zero-inflated and hurdle models of count data with extra zeros: examples from an HIV-risk reduction intervention trial. Am J Drug Alcohol Abuse. 2011 Sep;37(5):367-75.

24. Duflo E. Schooling and Labor Market Consequences of School Construction in Indonesia: Evidence from an Unusual Policy Experiment. Am Econ Rev. 2001;91(4):795-813.

25. Tsai AC, Venkataramani AS. The causal effect of education on HIV stigma in Uganda: Evidence from a natural experiment. Soc Sci Med. 2015 Oct;142:37-46.

26. Jackson C. Behavioral science theory and principles for practice in health education. Health Educ Res. 1997 Mar 1;12(1):143-50.

27. UNAIDS. Sexual Behavioural Change for HIV: Where Have Theories Taken Us? [Internet]. Geneva; 1999 [cited 2019 Sep 16] p. 60. (UNAIDS Best Practice Collection). Report No.: UNAIDS 99.27e. Available from: https://www.who.int/hiv/strategic/surveillance/pubchange/en/

28. Smoak ND, Scott-Sheldon LAJ, A M, Johnson BT, Carey MP. Sexual Risk Reduction Interventions Do Not Inadvertently Increase the Overall Frequency of Sexual Behavior: A Meta-Analysis of 174 Studies with 116,735 Participants. J Acquir Immune Defic Syndr 1999. 2006 Mar;41(3):374-84. 


\section{Supplementary Files}

This is a list of supplementary files associated with this preprint. Click to download.

- Additionalfile1.doc 